\title{
Calcium model for mammalian skeletal muscle
}

\author{
W. Wallinga-de Jonge H. B. K. Boom R. J. Heijink G. H. van der Vliet \\ Bio-information Group, Twente University of Technology, P.O. 217, 7500 AE Enschede, The Netherlands
}

\begin{abstract}
A model is presented describing quantitatively the events between excitation and force development in skeletal muscle. It consists of a calcium mediated activation model (c.m.a.m.) in series with a force generator model (f.g.m.). The c.m.a.m. was based on intracellular processes such as cisternal Ca-release, Ca-troponin interaction and Ca-uptake by SR. Ca-troponin complex concentration is an output of the c.m.a.m. and input of the f.g.m., the latter being a simplified actinmyosin cross-bridge model. Simulated and measured forces were compared for the rat slow (soleus) muscle. With the present structure and parameter values there is reasonable agreement between simulated and measured forces for single- and double-pu/se responses. The parameters of the f.g.m. mainly determine the rising phase of the twitch since the $C_{a}$-release is brief and the binding of $C_{a}$ to troponin is fast. In relaxation the Ca-troponin interaction and the Ca transporting ATPase parameters are also important. The behaviour of the muscle after a second action potential depends strongly on the level of $\mathrm{Ca}$ occupancy for both the troponin and $\mathrm{Ca}$ transporting ATPase.
\end{abstract}

Keywords-Calcium activation, Excitation-contraction coupling, Force development, Muscle model, Rat skeletal muscle

\section{Introduction}

IN recent years much information has been gained as to the processes involved in excitation-contraction (EC-) coupling of skeletal muscles. Sarcoplasmic reticulum is a key factor in EC-coupling (see FUCHS, 1974) and calcium distribution over a number of intracellular compartments also has an essential function. Excitation results in changed intercompartmental calcium flows (CHANDLER et al., 1976b; MILEd et al., 1977; POTTER et al., 1978; FroEHLICH and TAYLOR, 1975; WINEGRAD, 1970) the nature of which has been described in part quantitatively.

Only when the individual processes, as calcium release from sarcoplasmic reticulum (SR), calciumtroponin interaction and calcium uptake by SR, are combined, can the effect of a single process on the overall behaviour be analysed. This can be done only with help of a simulation model in which the individual processes can be recognised.

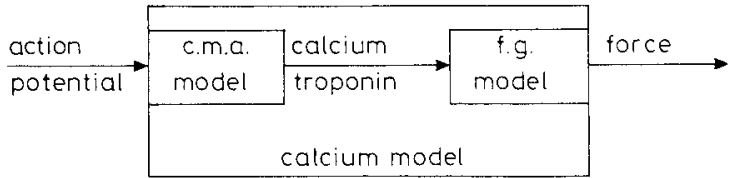

Fig. 1 Calcium mediated activation (c.m.a.-) model describing flows between and storage in the calcium compartments. Input is the action potential, output is calcium-troponin complex concentration. The latter is input for the force-generation (f.g.-) model

First received 8th July 1980 and in final form 13 th February 1981 $0140-0118 / 81 / 060734+15 \$ 01 \cdot 50 / 0$

(C) IFMBE: 1981
In this paper a calcium model is quantitatively described. It enables the simulation of calcium flows between the compartments and the calcium (complex) concentrations within them by using the relevant data of the individual processes.

Simulated forces generated by the model (Fig. 1) for single and repetitive stimulations are compared with experimental results obtained from rat skeletal muscle.

\section{Calcium mediated activation model (c.m.a.m.)}

\subsection{Outline of calcium pathways}

The c.m.a.m. describes the changes of the calcium (-complex) concentration in the intracellular compartments. Briefly, what happens is together with the calcium flows indicated in Fig. 2. During rest the calcium is stored for the greater part in the terminal cisternae of the sarcoplasmic reticulum (SR). As a result of an action potential over the $\mathrm{T}$-tubules calcium flows into the sarcoplasm (flow $\phi_{1}$ ), where it can bind to troponin $\left(\phi_{2}\right)$. A resulting calcium-troponin

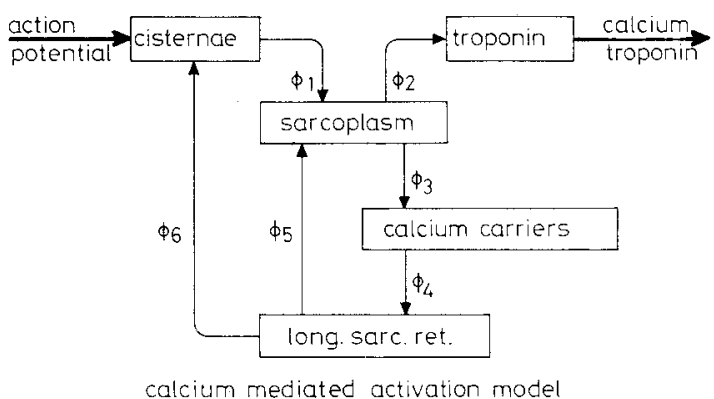

Fig. 2 Block diagram of the calcium compartments and calcium flows. Flows $(\phi s)$ are described in the text 
complex enables force generation. Dissociation of the calcium-troponin complex is forced by low sarcoplasmic calcium concentration realised by a calcium carrier pump in the longitudinal SRmembrane. Carriers remove calcium from sarcoplasm $\left(\phi_{3}\right)$ and transport it into the longitudinal SR against a calcium gradient $\left(\phi_{4}\right)$. During rest and after an action potential calcium leaks from the SR into the sarcoplasm due to the calcium gradient $\left(\phi_{5}\right)$. Inside the SR-system the calcium flows back to the cisternae by passive diffusion $\left(\phi_{6}\right)$. Owing to their significant calcium binding capacity, troponin and calcium carriers are considered as separate compartments.

The calcium concentration is assumed to be uniform inside each compartment, implying that all intracompartmental diffusion processes are virtually instantaneous.

\subsection{Calcium release from $S R\left(\phi_{1}\right)$}

The mechanism of the calcium release from the terminal cisternae is not yet clear. For skeletal muscle, the depolarisation of the tubular membrane probably initiates the enhancement of the calcium permeability of the terminal cisternal membrane (ENDO, 1977).

The sarcolemmal action potential also propagates into and along the T-tubules (GONZALEZ-SERRATOS, 1971). The time course of the tubular membrane depolarisation is not known; detailed information about propagation velocity of the action potential and eventual damping is lacking (ADRIAN and PEACHEY, 1973). Consequently, these aspects are not incorporated in the c.m.a.-model. The depolarisation of the whole tubular membrane was taken as indentical to sarcolemmal depolarisation. The impact of this assumption on the simulations is discussed in Section 6. The course of the sarcolemmal action potential has been derived from HANSON (1974) for rat soleus muscle fibres. The resting membrane potential is $-73.7 \mathrm{mV}$; the amplitude $93.8 \mathrm{mV}$. The calcium release flow is calculated from

$\phi_{1}(t)=n_{c h} \cdot A_{T} \cdot N^{2}(t) \cdot \phi_{c h} \cdot \frac{[C a(t)]_{c}-[C a(t)]_{s}}{[C a]_{C, r e s t}-[C a]_{\text {S.rest }}}$

where

$n_{c h}$ is the maximum number of open calcium channels per unit cisternal membrane surface,

$A_{T}$ the cisternal membrane surface concerned in release,

$N^{2}(t)$ the fraction open calcium channels,

$\phi_{c h}$ the calcium capacity per (open) channel,

$[\mathrm{Ca}]_{C}$ the calcium ion concentration in cisternae and

$[\mathrm{Ca}]_{S}$ the calcium ion concentration in sarcoplasm.

The component elements of eqn. 1 will now be introduced consecutively. Calcium channels have been claimed to occur in the cisternal membrane (see ENDO,
1977). The number of calcium channels per surface unit was equated to the number of 'feet' between the tubular and SR-membrane per unit surface in frog muscle (FRANZINI-ARMSTRONG, 1970).

The surface of the SR-membrane that contains the calcium channels was taken the same as the surface of the T-system

Calcium channels may occur in two states in the model: open and closed. We assumed that the fraction of open channels depends on membrane potential and time, since $N(t)$ behaves like a Hodgkin-Huxley variable

$$
\frac{d N(t)}{d t}=\alpha\{1-N(t)\}-\beta . N(t)
$$

where

$$
\alpha=\frac{\alpha_{\max }(E-\bar{V}) / k}{1-\exp (\bar{V}-E) / k}
$$

and

$$
\beta=\frac{\beta_{\max }(\bar{V}-E) / k}{1-\exp (E-\bar{V}) / k}, .
$$

where

$\alpha_{\max }, \beta_{\max }, \bar{V}$ and $k$ are constants and

$E$ is the transmembrane potential.

The behaviour of the calcium channels is not known. The value of $\phi_{c h}$, the flow per channel in the rest situation, and which was taken as a constant, was obtained from the assumption that about $0.1 \mu \mathrm{molCa}$ per $\mathrm{ml}$ sarcoplasm is released during a single twitch (BAYLOR et al., 1979a).

For a given $N^{2}(t)$ function the product of $n_{c h}, A_{T}$ and $\phi_{c h}$ determines the calcium release in the twitch (the influence of the last term in eqn. 1 is quite small). So the release of a certain amount of calcium can also be realised by another combination of values of $n_{c h}$ and $\phi_{c h}$.

The calcium flow through each open channel was assumed to depend on the calcium concentration gradient over the membrane. The last factor of eqn. 1 equals 1 in the rest situation. It is always less than. 1 after release of calcium from the cisternae into the sarcoplasm and thereby reduces the calcium flow.

\subsection{Calcium binding to troponin $\left(\phi_{2}\right)$}

The troponin- $\mathrm{C}$ molecule of skeletal muscle has two specific calcium binding sites and two competitive $\mathrm{Ca}^{2+}-\mathrm{Mg}^{2+}$ binding sites (POTTER and GerGely, 1975; HAIECH et al., 1979).

We assumed that there is no interdependency between the binding to specific calcium and $\mathrm{CA}^{2+}-\mathrm{Mg}^{2+}$ sites, so that the troponin molecules can be thought to be split into two sets: troponin with two specific calcium sites and troponin with two $\mathrm{Ca}^{2+}-\mathrm{Mg}^{2+}$ sites. The amount of both 'sorts' of troponin is then equal to the total amount of troponin. 
From experiments on rabbit fast skeletal muscle troponin it would appear that the reaction rates for the binding of the first and second calcium ion are equal for each type of binding site, while the affinity of calcium for the $\mathrm{Ca}^{2+}-\mathrm{Mg}^{2+}$ is much higher than for the specific sites (POTTER et al., 1978; HAIECH et al., 1979). The following reactions were assumed to occur:

$$
\begin{aligned}
& \mathrm{Ca}+\mathrm{Tn}_{\mathrm{s}} \underset{\mathrm{k}_{2, \mathrm{~s}}}{\stackrel{\mathrm{k}_{1, s}}{\rightleftharpoons}} \mathrm{CaTn_{s }} \\
& \mathrm{Ca}+\mathrm{Ca} T n_{\mathrm{s}} \underset{k_{2, s}}{\stackrel{k_{1, s}}{\rightleftharpoons}} \mathrm{Ca} a_{2} T n_{\mathrm{s}} \\
& \mathrm{Ca}+\operatorname{Tn}_{n} \underset{k_{2, n}}{\stackrel{k_{1, n}}{\rightleftharpoons}} \mathrm{CaTn_{n }} \\
& \mathrm{Ca}+\mathrm{CaT} n_{n} \underset{k_{2, n}}{\stackrel{k_{1, n}}{\rightleftharpoons}} \mathrm{Ca} a_{2} T n_{n}
\end{aligned}
$$

Assuming a homogeneous distribution of troponin in the sarcoplasm, these reactions result in a net calcium flow from sarcoplasm to troponin:

$$
\begin{aligned}
\phi_{2}(t)= & V_{S}\left\{\frac{d\left[C a T n_{s}(t)\right]}{d t}+2 \frac{d\left[C a_{2} T n_{s}(t)\right]}{d t}\right. \\
& \left.+\frac{d\left[C a T n_{n}(t)\right]}{d t}+2 \frac{d\left[C a_{2} T n_{n}(t)\right]}{d t}\right\}
\end{aligned}
$$

where

$V_{S}$ is the sarcoplasm volume,

$\left[T n_{s}\right]$ the troponin concentration with two specific $\mathrm{Ca}^{2}+$ sites in sarcoplasm* and

$\left[T n_{n}\right]$ the troponin concentration with two $\mathrm{Ca}^{2+}-\mathrm{Mg}^{2+}$ sites in sarcoplasm.

In the model the $\mathrm{Mg}^{2+}$-concentration was taken constant (BAYLOR et al., 1979b). The reaction rate constants for the $\mathrm{Ca}^{2+}-\mathrm{Mg}^{2+}$ sites (POTTER and GERGELY, 1975; HAIECH et al, 1979) for a $\mathrm{Mg}^{2+}$. concentration of $1 \mathrm{mM}$ (BAYLOR et al., 1979b) were used.

The $\mathrm{Ca}_{2} \mathrm{Tn}_{s}$ complexes enable interaction between actin and myosin (POTTER and GERGELY, 1975; JoHNSON et al., 1979). This is described in the Section on the force generation model.

\subsection{Calcium transport from sarcoplasm to the longitudinal $S R\left(\phi_{3}\right.$ and $\left.\phi_{4}\right)$}

The calcium-transporting carriers in the membranes of the longitudinal SR have been studied extensively with fragmented SR-vesicles (FSR) (see TADA et al., 1978). The transport consists of at least six chemical reactions (MARTONOSI, 1971; KANAZAWA et al., 1971). Most of the individual reaction rate constants, however, have not been described quantitatively.

* Tn is negatively loaded; its valency has been omitted for simplicity; this has been done also at other places for other molecules
Therefore, we use an appreciably simplified description of the carrier transport containing the most essential aspects.

The processes involved in calcium removal from sarcoplasm are comprised in $\phi_{3}$, and processes involved in calcium release into longitudinal $S R$ are comprised in $\phi_{4}$.

Each carrier molecule $E$ has two equivalent binding sites for calcium (MARTONOSI, 1973). The binding occurs at the sarcoplasmic side of the membrane. It is very fast and competes strongly with the binding to troponin:

$$
\begin{aligned}
& C a_{S}+E \underset{k_{4}}{\stackrel{k_{3}}{\rightleftharpoons}} C a E \\
& C a_{S}+C a E \underset{k_{4}}{\stackrel{k_{3}}{\rightleftharpoons}} C a_{2} E
\end{aligned}
$$

If these reactions were thought to occur in a small volume $V_{e q}$, in which the reaction constituents are distributed homogeneously, then the calcium flow from sarcoplasm to carrier is given by

$$
\begin{aligned}
\phi_{3}(t) & =V_{e q}\left\{k_{3}[C a(t)]_{S}([E(t)]+[C a E(t)])\right. \\
& -k_{4}\left([C a E(t)]+\left[C a_{2} E(t)\right]\right\}
\end{aligned}
$$

where

$[E]$ is the concentration of calcium transporting ATPase (calcium sites unoccupied) in $V_{e q}$.

The carriers transport the calcium to the reticulum side of the membrane, where they lose their high affinity for calcium. Consequently the calcium ions are released into the lumen of the SR. In the model this was assumed to occur in two stages:

$$
\begin{aligned}
& C a_{2} E \stackrel{{ }^{k}}{\rightarrow} C a_{L}+C a E^{\prime} \\
& C a E^{\prime} \stackrel{{ }^{\circ}}{\rightarrow} C a_{L}+E
\end{aligned}
$$

where

$$
C a_{L} \text { is calcium inside longitudinal SR. }
$$

The reaction rate constant of the inverse reaction is very small (FROEHLICH and TAYLOR, 1975) so that it could be omitted. In contrast to the fast binding at the sarcoplasmic side, the release into the SR-lumen is very slow. It is described by:

$$
\phi_{4}(t)=V_{e q}\left\{k_{5}\left(\left[C a_{2} E(t)\right]+\left[C a E^{\prime}(t)\right]\right)\right\} .
$$

where

$\left[\mathrm{CaE}^{\prime}\right]$ is the concentration of calcium transporting ATPase, loaded with one calcium ion, intermediate at the lumen side of the SR membrane. 
2.5 Calcium leakage from longitudinal $S R$ into sarcoplasm $\left(\phi_{5}\right)$

At rest and during prolonged muscle activity the calcium concentration inside the longitudinal SR is much higher than in the sarcoplasm. This results in a flow from SR to sarcoplasm (WEBER et al., 1966). Since the nature of this flow is unknown, it is described in the model as a passive diffusion leakage flow:

$$
\phi_{5}(t)=D_{1}\left([\mathrm{Ca}(t)]_{L}-[\mathrm{Ca}(t)]_{S}\right) . \quad . \quad .
$$

where

$$
D_{1} \text { is a diffusion constant. }
$$

2.6 Calcium backflow from longitudinal $S R$ to terminal cisternae $\left(\phi_{6}\right)$

The longitudinal calcium flow within the SR to the terminal cisternae can be studied only in intact muscle fibres. Quantitative data of WINEGRAD (1970) (frog muscle) indicate that it is controlled by the concentration gradient:

$$
\phi_{6}(t)=D_{2}\left([\mathrm{Ca}(t)]_{L}-[\mathrm{Ca}(t)]_{C}\right) . \quad .
$$

where

$D_{2}$ is a diffusion constant and

$\mathrm{Ca}_{C}$ free calcium ions in terminal cisternae.

The greater part of the calcium in the cisternae is bound to proteins in a fast equilibrium (MARTONOSI, 1971). In our model only $1 \%$ is present in free ionised form. An instantaneous relation between free and bound calcium is used:

$$
[\mathrm{Ca}(t)]_{C}=0.01[\mathrm{Ca}(t)]_{C, \text { total. }} .
$$

where $C a_{C, \text { total }}$ is the sum of free and bound calcium in the terminal cisternae.

\subsection{Additional equations}

In the above Sections the intercompartmental flows were expressed in terms of the underlying processes. To complete this model additional equations are needed to relate compartmental calcium concentrations to the flows. Differential equations to describe the calcium concentrations in the compartments involved follow from the differences between the flows in and out of these compartments. Also the system was supposed to be closed so the quantities of calcium, troponin and ATPase are constant.

The resting values of the compartmental concentrations were derived by putting all time derivatives zero. These values have been used as the starting values for the integration procedure.

\section{Force generation model}

Our force generation model is derived from the cross-bridge model of JULIAN et al. (1974). Fig. 3 indicates schematically the processes determining the number of force generating cross-bridges. The presence of binding places on actin for coupling with free myosin heads (AS in Fig. 3) depends on the troponin state. When both calcium specific binding sites of one troponin (resulting in $\mathrm{Ca}_{2} \mathrm{Tn}_{\mathrm{s}}$ ) have been occupied, 7 actin binding places $A S$ are recruited (PERRY, 1979). A change in $[A S]$ depends on its relations illustrated in Fig. 3 and on its production by $\mathrm{Ca}_{2} \mathrm{Tn}_{s}$ :

$$
\begin{array}{r}
\frac{d[A S(t)]}{d t}=k_{d}\left[A_{\beta}(t)\right]-k_{a}[A S(t)][D(t)] \\
+7 \frac{d\left[C a_{2} T n_{s}(t)\right]}{d t}
\end{array}
$$

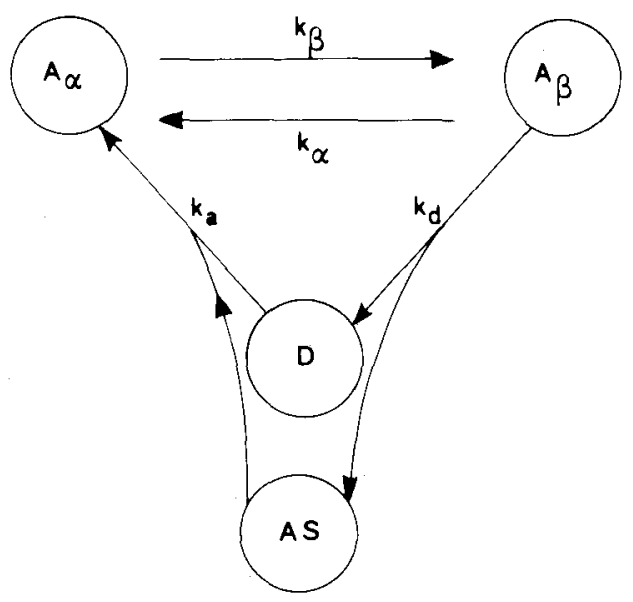

Fig. 3 Diagram of force-generation model with $k_{a}, k_{d}, k_{x}$ and $k_{\beta}$ reaction rate constants.

$A S=$ active sites; available binding places on actin for free myosin heads

$D=$ free myosin heads

$A_{x}=$ non-force generating cross-bridges

$A_{\hat{f}}=$ force generating cross-bridges

The symbols are defined in the legend of Fig. 3. Eqn. 14 implies that the concentration of $\mathrm{Ca}_{2} T n_{s}$ does not depend on the state of the myosin head $\left(D, A_{x}\right.$ or $\left.A_{\beta}\right)$ and a change in $\left[\mathrm{Ca}_{2} T n_{\mathrm{s}}\right]$ only influences $[\mathrm{AS}]$. Muscle force depends on the number of parallel muscle fibres whose effects summate linearly. The force per muscle fibre depends on the number of forcegenerating cross-bridges per half sarcomere (HUXLEY, 1974). If the force exerted by all force generating crossbridges was assumed to be uniformly distributed, then:

$$
F(t)=F_{b r} C\left[A_{\beta}(t)\right] .
$$

where

$$
\begin{aligned}
& F_{b r} \text { is the mean cross-bridge force and } \\
& C \text { is a constant. }
\end{aligned}
$$




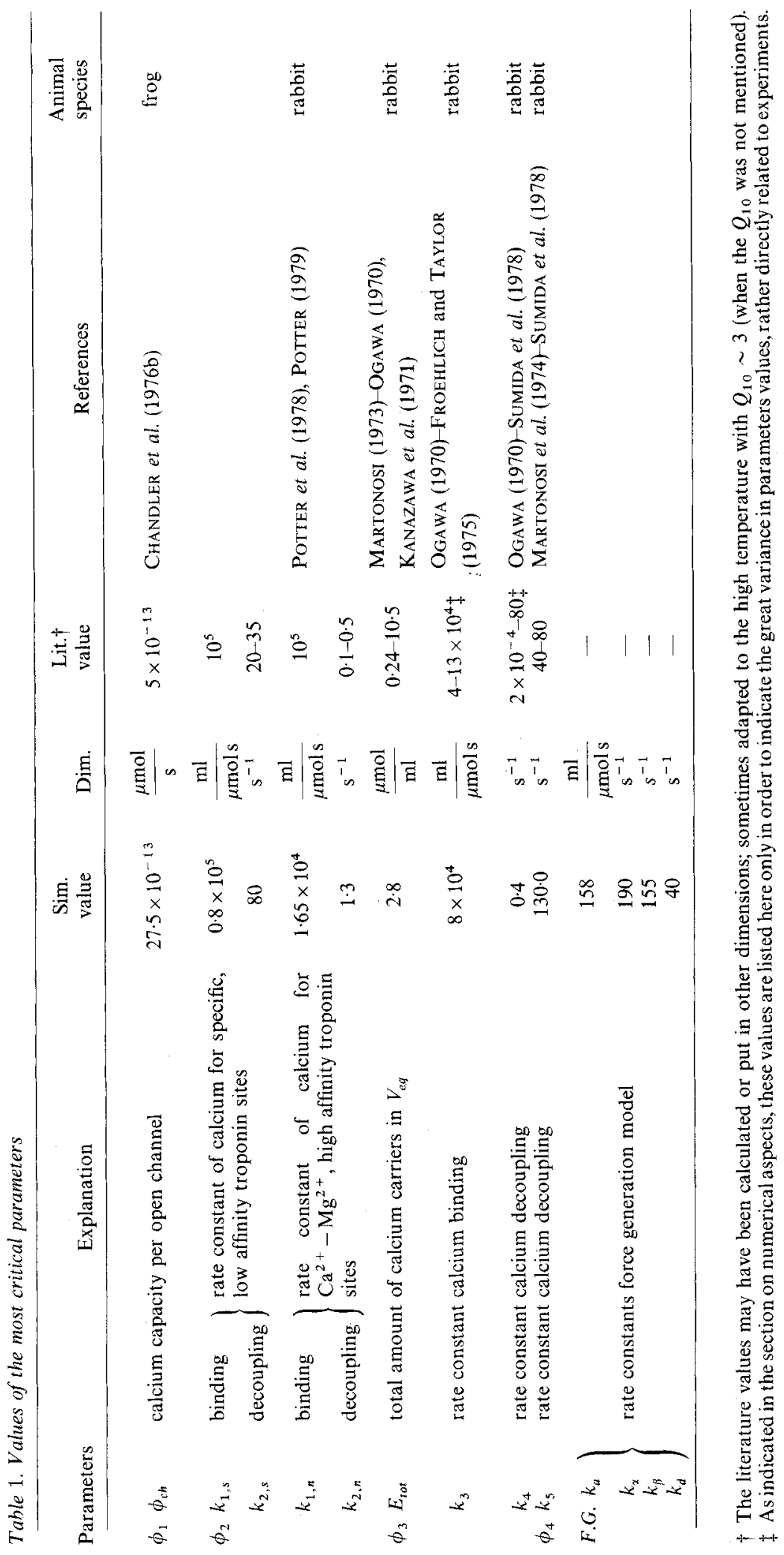




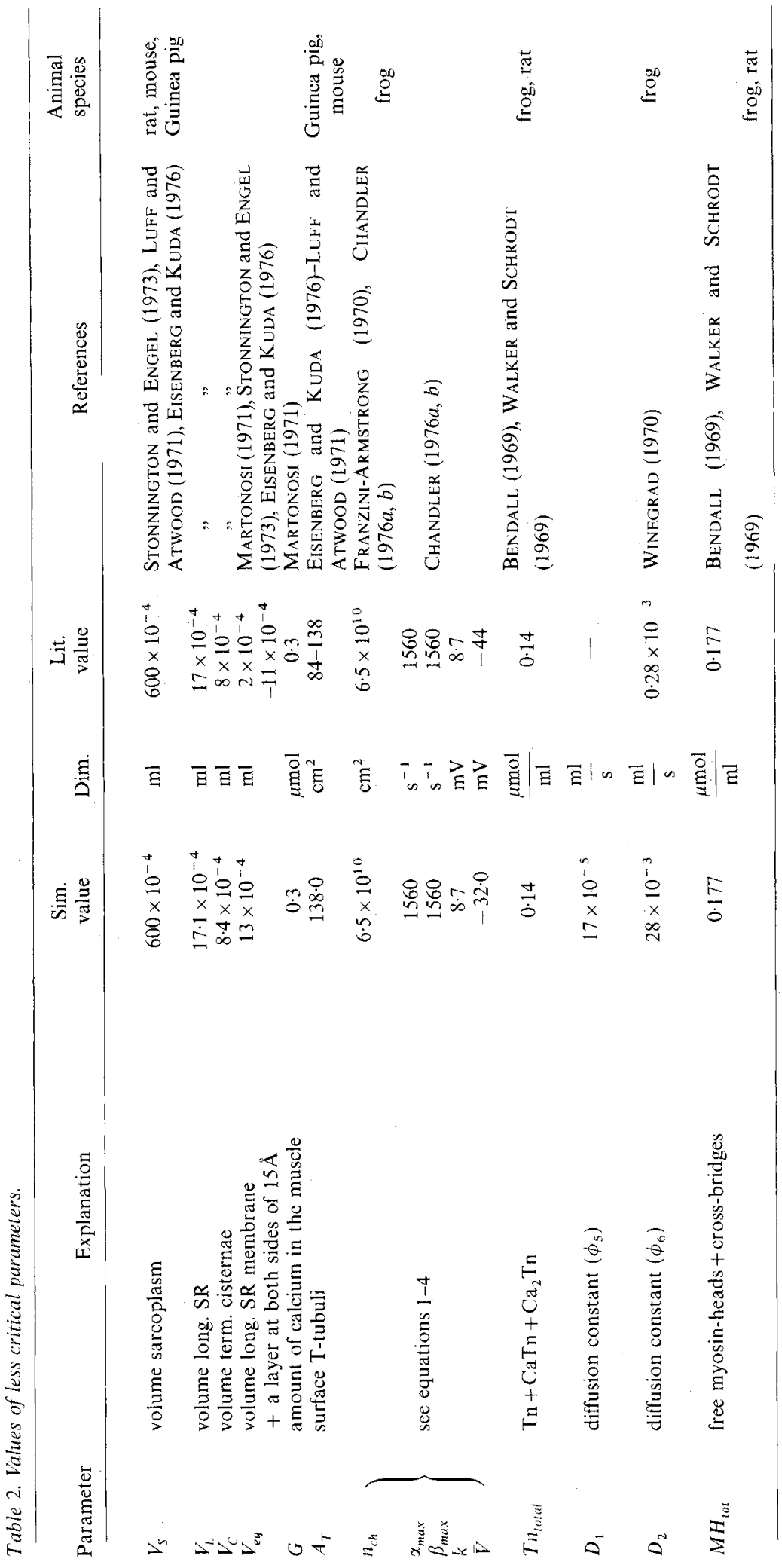




\section{Numerical aspects}

In this study model responses, calculated with the help of processes described in the literature, and actual muscle performance after electrical stimulation were compared quantitatively. Therefore, the literature dealing with the subcellular mechanism of ECcoupling was searched and the information obtained was incorporated, after any necessary transformation or scaling, into the model. The force output of the model was then compared with the results of suitably designed measurements.

In the course of doing this a number of problems arose. As already mentioned, virtually all the component processes have been described and parameter values published in the literature. In most cases, however, the conditions of the measurements differ from those in the muscle for which the model was intended to be valid. For instance, the temperature could have been more than $30^{\circ} \mathrm{C}$ lower, a different sort of animal may have been used, or concentrations may not be comparable with those in actual muscle conditions. This resulted - at least for some parameters - in a large degree of uncertainty (see Tables 1 and 2). How this problem was further dealt with will be described below after introducing the experimental procedure.

Isometric force developed by the slow $\mathrm{m}$. soleus of albino rats (Nembutal anesthesia) was measured in vivo at $37^{\circ} \mathrm{C}$. Supramaximal stimulation pulses with a duration of $50 \mu$ s were applied to the nerve, while the muscle was adjusted to the optimum twitch length. Detailed information about experimental set-up and results has been described before (WALLINGA-DE JONGE et al., 1980). Twitches, double-pulse responses with various interval times, tetani and prolonged series of twitches were measured. Characteristics as indicated in Fig. 4 were derived from twitch and double pulse responses and compared with those derived from the simulated patterns.
Actual model parameters were found as follows. In the first instance the values for the f.g.m. were fully unknown and had to be found by trial and error in such a way that a twitch was simulated accurately (least summed squares of differences between simulated and measured characteristics). The mean force per cross-bridge ( $F_{b r}$ in eqn. 15) was derived from measured tetanic force (WALLINGA-DE JONGE, 1980) taking into account the organisation of sarcomeres and myofilaments, and data from the literature (SZENT-GYÖRGYI; 1975; GRAY and GONDA, 1978). The two sets of values were in good agreement and indicated $6 \mathrm{pN}$ to be a reasonable approximation.

The parameter values of the c.m.a.m. which are not accurately known (especially the nine mentioned in Table 1) were adjusted so as to minimise the deviation between simulated and experimental force patterns. In most cases an optimal fit could be obtained with parameter values in accordance with the literature (Tables 1 and 2), but note the uncertainty range mentioned above.

BAYLOR et al. (1979a) calculated on the basis of their arsenazo III-measurements in frog muscle fibres that a single action potential releases about $0.1 \mu$ mol calcium per ml sarcoplasm. In our model an action potential arriving in the resting state releases $0.14 \mu \mathrm{mol}$ calcium $/ \mathrm{ml}$. This amount is sufficient for the generation of an adequate twitch. This indicates the greater amount estimated by ENDO (1977), about $0.4 \mu \mathrm{mol} / \mathrm{ml}$, is not required.

The greatest differences occur in the referenced values of the parameters of the calcium transport from sarcoplasm to the longitudinal SR. The great ranges given in Table 1 for $k_{3}\left(1: 310^{4}\right)$ and $k_{4}\left(1: 410^{5}\right)$ make them virtually unknown. Moreover, the in vivo calcium transport situation does not allow direct comparison with the literature values for the reaction constants defined.

Realisation of the model was further complicated by

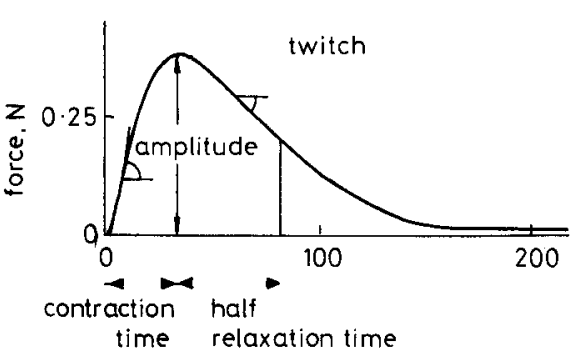

Fig. 4 Definition of characteristics of force patterns for twitch and double pulse response

Contraction time = time interval between onset of force generation and time of maximum force

Half relaxation time $=$ time interval between moment of maximum force and time at which force amplitude

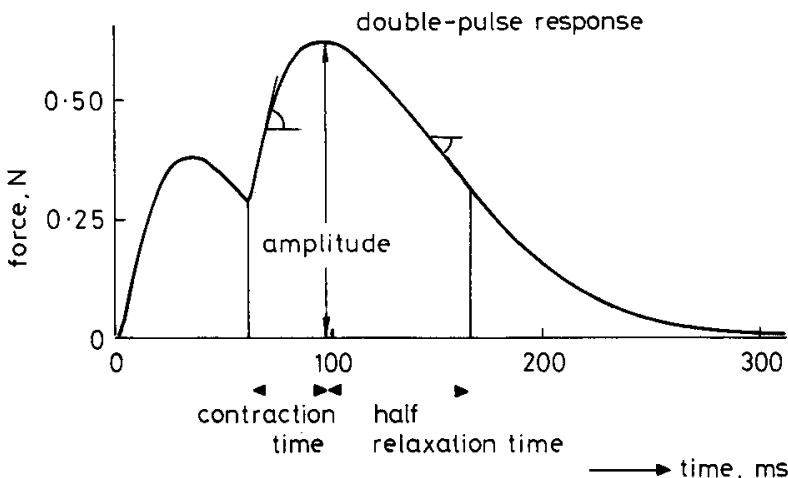

decreased to a half

Maximum positive slope $=$ max of derivative of force in the rising phase

Maximum negative slope $=$ min of derivative of force, in the descending phase

Slopes are indicated with an angle-sign 
the fact that it represents a fairly large and stiff set of differential equations. This necessitated widely different integration step lengths in the time. The special c.s.m.p. (continuous simulation modeling program) variable step integration procedure for stiff differential equation systems (with large differences in time constants) was used. A twitch simulation thus takes approximately $1 \mathrm{~s}$ of c.p.u.-time.

\section{Force simulation results}

The parameter set-ultimately chosen produced the simulated twitch shown in Fig. $5 a$ from a single action potential. The resemblance between simulated and measured twitch patterns is good, although the form of the descending phases differ slightly. This is reflected by the difference in values of the maximum negative slope in the simulation and measurement, while the values of the other characteristics agree. Although reasonable twitch force patterns were obtained with a number of different parameter sets, only two of these showed acceptable behaviour with respect to double
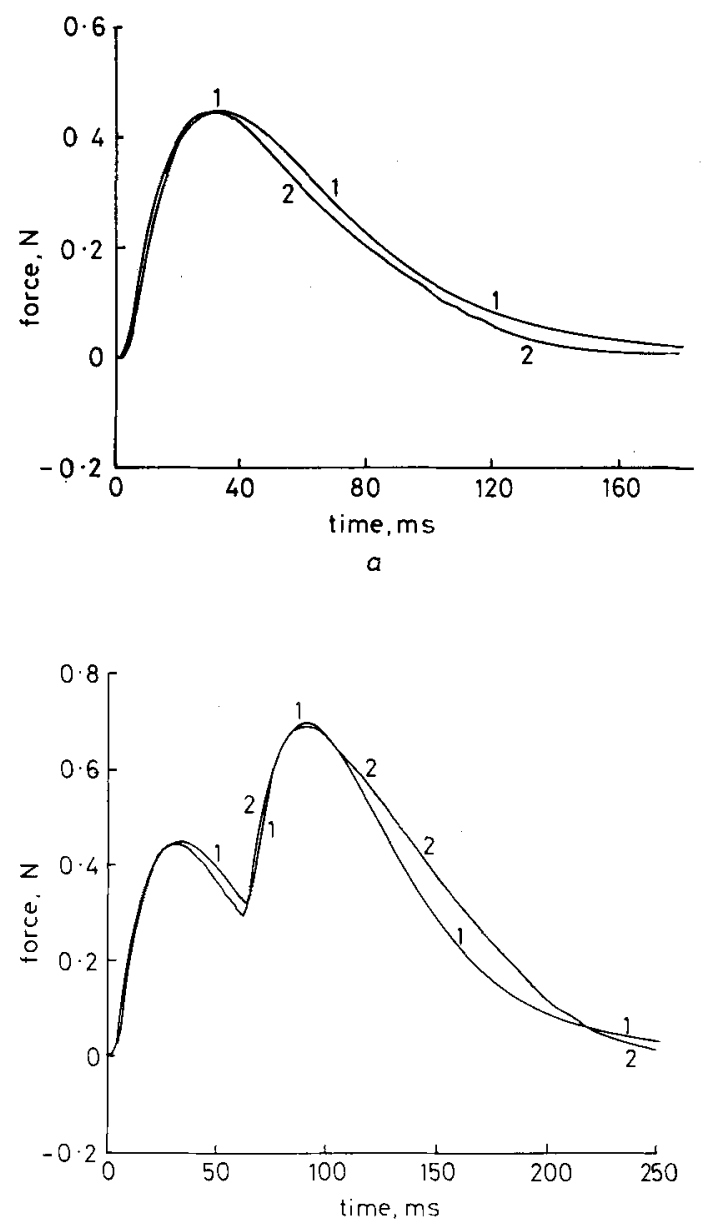

$b$ pulse responses. They differed with respect to only two parameter values of the force generation model $\left(k_{\alpha}\right.$ and $\left.k_{\beta}\right)$.

The simulated and measured force of a double pulse response are plotted in Fig. $5 b$. In contrast to the twitch the simulated relaxation is faster than the measured one. The results at different interval times for the characteristics indicated in Fig. 4 are depicted in Fig. 6. Note that the normalised amplitude and maximum positive slope agree satisfactorily for simulated and measured patterns in the tested interval time range ( 5 to $200 \mathrm{~ms}$ ). The contraction time of the simulated double pulse responses however is always too small. It is apparent from Fig. $6 d$ that the maximum negative slope decreases with increasing interval time. This decrease is less pronounced for the simulations. If the characteristic values of simulated and measured twitch agree, the normalised plots of Fig. 6 can be interpreted directly in a quantitative way. This holds for all characteristic values except for the maximum negative slope, the value of which for the simulated twitch is too small. At the smallest interval
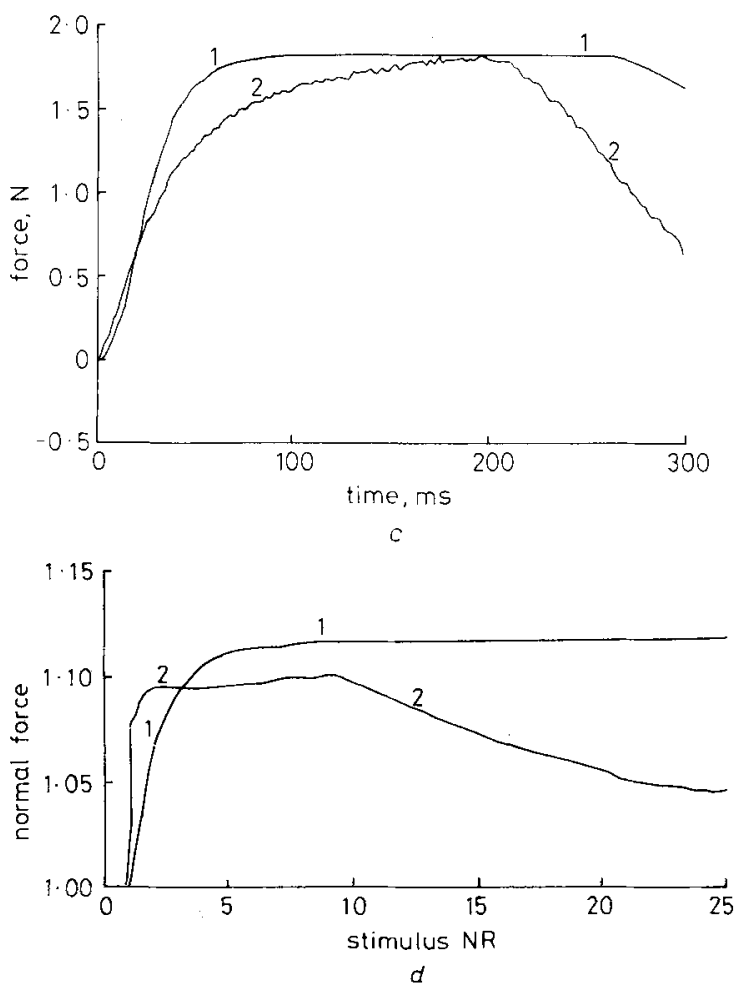

Fig. 5 Comparison of simulated (1) and measured (2) force patterns for twitch (a), double pulse response with $60 \mathrm{~ms}$ interval $(b)$, tetanus with 20 stimuli, $10 \mathrm{~ms}$ intervals (c), and prolonged series of twitches with $200 \mathrm{~ms}$ interval $(d)$. In (a)-(c) the force is plotted as function of the time, in $(d)$ the force is normalised with respect to the force amplitude of the first twitch, and plotted against the rank order of the twitches 
times the difference in the absolute values of the maximum negative slope of simulated and measured double pulse responses is reduced with respect to that of a twitch.

Deviations of the model are appreciable in the tetanus situation. The ascending phase of the simulated tenanus is too fast, while the descending phase is too slow (Fig. 5c). The most conspicuous deviation occurs after stimulation has finished: the simulated force stays high, while the measured force decreases gradually. This appears to be associated with the value chosen for the total amount of calcium (see discussion). The effect disappears if this amount is

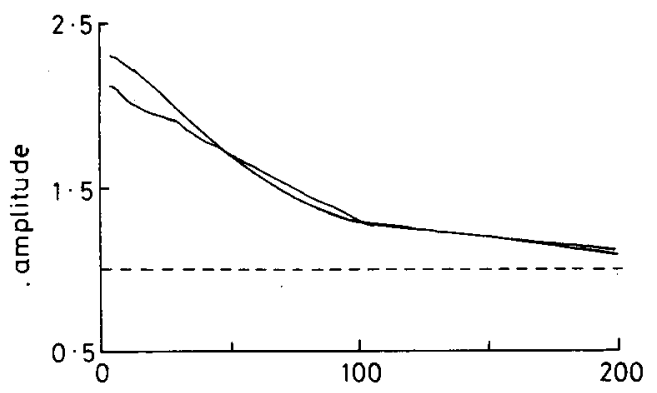

reduced.

Prolonged series of twitches were also studied because they offer the possibility of analysing the measure to which the system is returned to the resting state after a twitch. That this is not entirely the case is found experimentally since the amplitude of twitches changes during such a series. The plots of the amplitude of twitches, with an interval time of $200 \mathrm{~ms}$, show that during the onset the model performs reasonably well (Fig. 5d). In the simulations the twitch amplitude stays constant from the 7 th twitch upwards, in the experiment it decreases gradually from about the 10th twitch (WALlinga-DE JONGE, 1980).

Fig. 6 Comparison of simulated (1) and measured (2) characteristic values of double pulse responses for different interval times $(5,10,15,20,30,40,60,80,100$ and $200 \mathrm{~ms})$. Ordinate values are normalised to the corresponding values for a single twitch (indicated for clarity by the broken line)
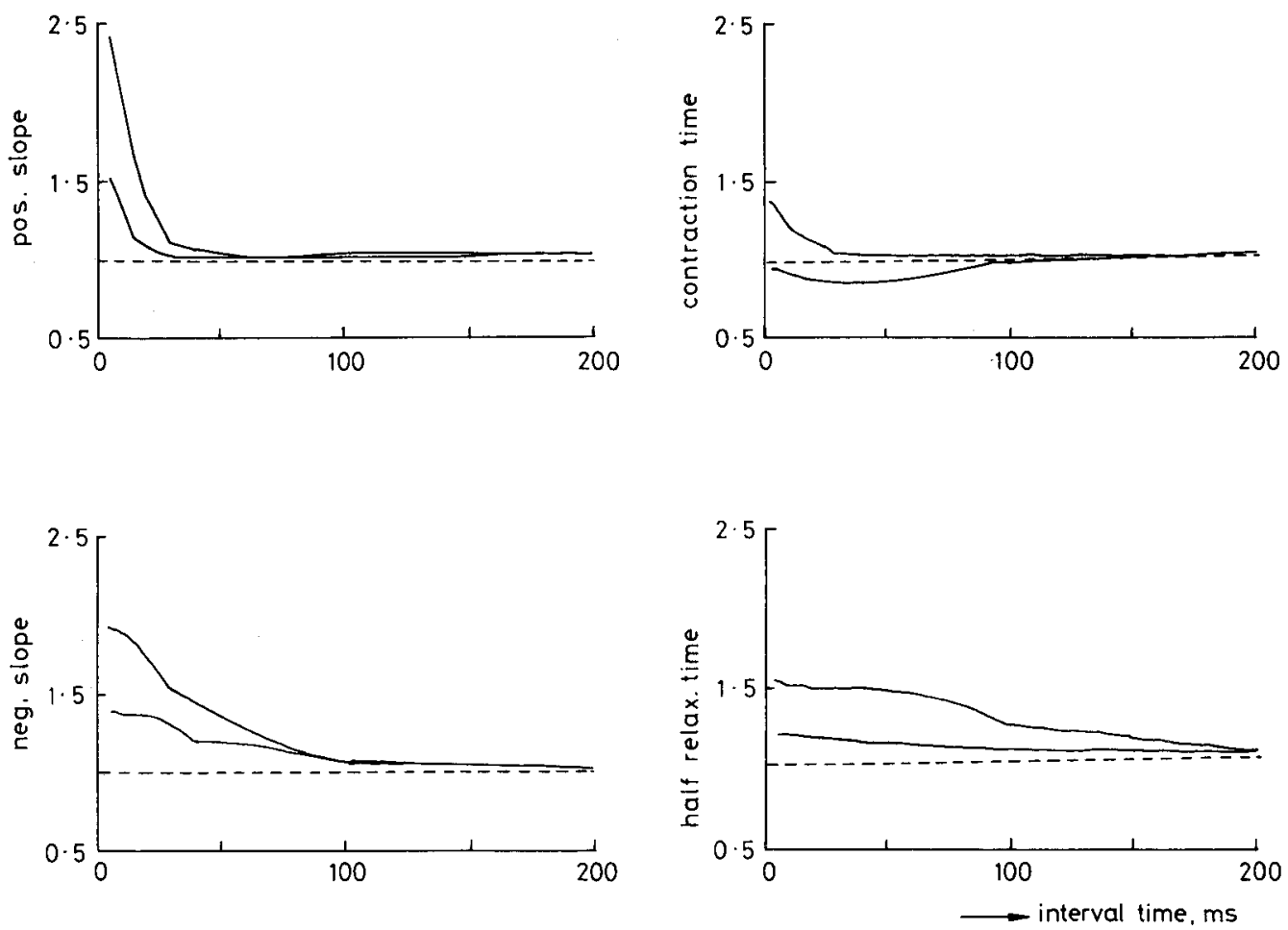

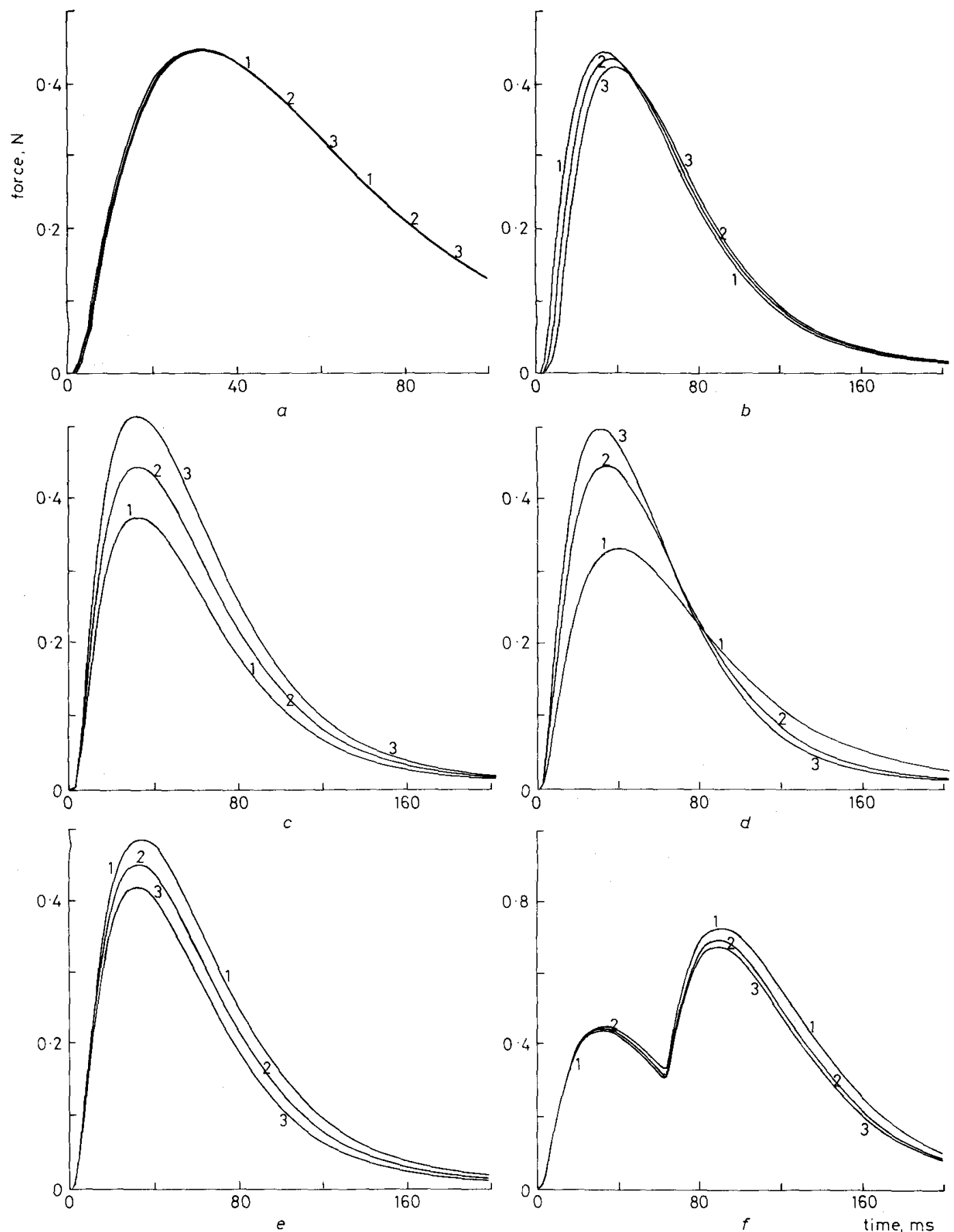

Fig. 7 Some examples of sensitivity of the model to parameter values. a-e for twitch, ffor double pulse response with $60 \mathrm{~ms}$ interval time. In all plots force versus time.

(a) same amount of calcium released for the three curves, but duration of calcium release resp. 0.2 , 1.0 and $2.2 \mathrm{~ms}$

(b) further increasing durations 1: $2.0 \mathrm{~ms}, 2: 6.0 \mathrm{~ms}$, 3: $10.0 \mathrm{~ms}$

(c) calcium capacity per channel $\left(\phi_{c h}\right)$ changed 1: $-11 \%, 2$ : optimised value, $3:+15 \%$

(d) changed interaction of calcium with troponin ( $k_{1, s}$ and $k_{2, s}$ changed comparably so that $k_{1, s} / k_{2, s}$ is constant) $1:-50 \%, 2$ : optimised value, $3:+50 \%$

(e) changed amount of calcium carrier (E) $1:-14 \%$, 2: optimised value, $3:+14 \%$

(f) changed release of calcium from carrier $\left(k_{5}\right) 1$ : $-38 \%, 2$ : optimised value, $3:+38 \%$ 
6 Influence of parameter values on force development

Since the literature values of the parameters occasionally show appreciable uncertainty (see Tables 1 and 2), it is of interest to test the model sensitivity for a number of parameters. The most prominent results with respect to c.m.a.-model parameters have been plotted in Fig. 7. A general aspect found is that the changes in contraction and half relaxation time are always similar with respect to direction, although they sometimes differ in extent. This fact implies a considerable degree of dependency between some parameters at least and causes difficulties in simultaneously realising correct contraction and half relaxation times. Here either the contraction time was too short or the relaxation was too slow.

The duration of the calcium release, which is directly related to the (unknown) form of the tabular action potential, is varied from 0.2 to $2.2 \mathrm{~ms}$ (Fig. 7a), conserving the amount of calcium released: the three twitches are indistinguishable. When the same amount is released during times $>2.2 \mathrm{~ms}$, the twitch is slower and reaches a lower amplitude (Fig. $7 b$ ). Thus, in the case of a short duration release, only the released amount is important rather than the course of the release.

In reality the total amount of calcium released per action potential is uncertain (see Section 4 on numerical aspects). One way of adapting the released amount is with the help of the capacity of the calcium channels $\phi_{c h}$ (1). A change of $\phi_{c h}$ influences both amplitude and form of the twitch, at least in the range shown (Fig. 7c).

Because the duration of the $T$-tubule depolarisation is expected to be less than $10 \mathrm{~ms}$, the main action of the action potential is controlling the amount of calcium released. Therefore changes in action potential will have effects comparable with changes in $\phi_{c h}$, displayed in Fig. $7 c$.

There is a strong competition between the calcium binding to troponin and the calcium transporting ATPase. The effect of a simultaneous change in $k_{1, s}$ and $k_{2, s}$ (the reaction rate constants for calcium binding to and decoupling from the specific sites of troponin respectively) without change in the affinity constant $k_{1, s} / k_{2, s}$ is shown in Fig. $7 d$. This change markedly influences the form of the twitches. An enhancement introduces an increase of the twitch amplitude and a shortening of both contraction and half relaxation time.

Model performance depends fairly strongly on the amount of calcium transport ATPase with the chosen parameter set. An adaptation of the ATPase amount changes the twitch amplitude and particularly the relaxation of the twitches (Fig. 7e). The change in the twitch form, caused by variation of the reaction rate for calcium binding to the ATPase $\left(k_{3}\right)$, are not shown. An enlargement of $k_{3}$ reduces the amplitude, and shortens the half relaxation time more than the contraction time. Finally, the effect of a change in reaction rate constant $k_{5}$ (the decoupling of calcium from the
ATPase at the lumen side of the SR-membrane) does not influence the twitch noticeably, but it is an important parameter in the quotient of double pulse amplitude/twitch amplitude (Fig. $7 f$ ). If $k_{5}$ increases, the resting state will be reached sooner and there will be relatively less effect of the second stimulus.

When each of the four reaction rate constants in the f.g.m. is varied, the time course of the twitch changes. In conclusion, all the simulations described in this
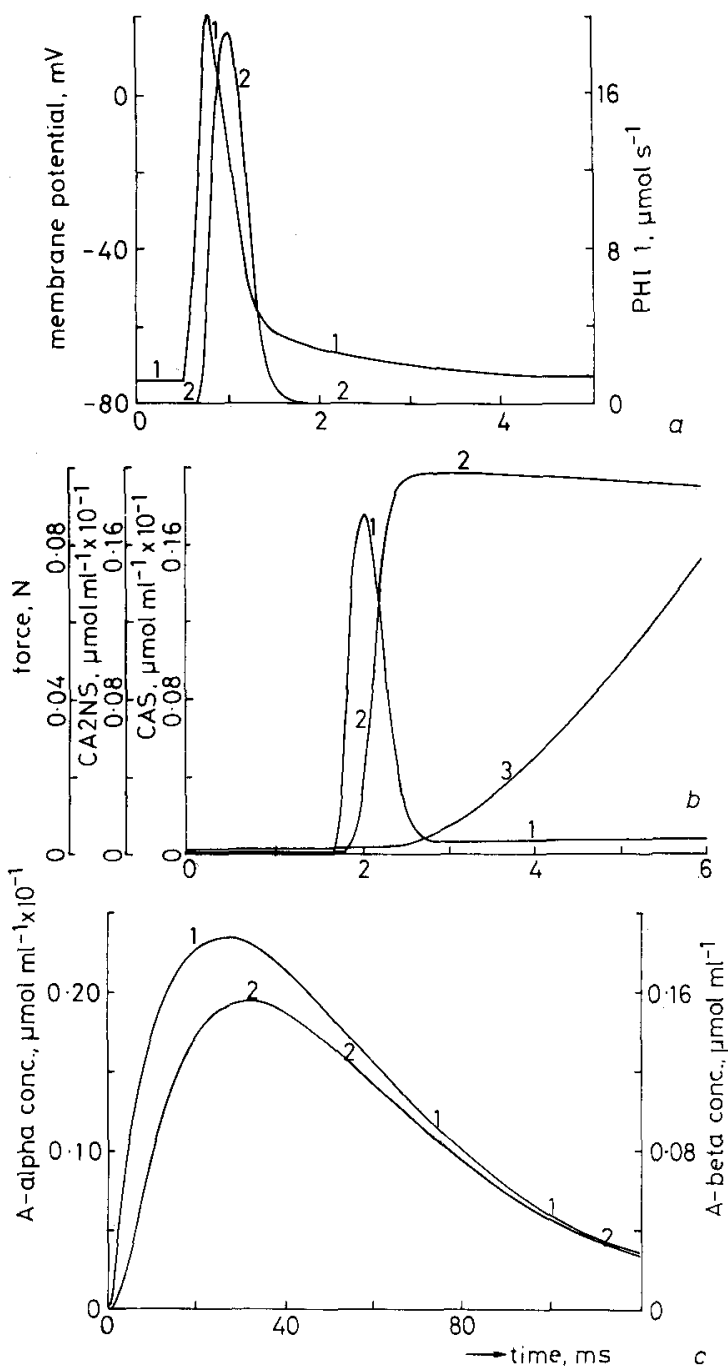

Fig. 8 Processes from action potential to force generation. In all cases a single action potential occurs, but its starting moment is different [in (a) at $0.5 \mathrm{~ms}$, in (b) at $1.5 \mathrm{~ms}$ and in $(\mathrm{c})$ at $0.5 \mathrm{~ms}$ ]

(a) $1=$ membrane potential $(m V), 2=\phi_{1}$ (calcium release flow in sarcoplasm, umols $^{-1}$

(b) $1=\left[\mathrm{Ca}^{2+}\right]_{s} \mu \operatorname{molml} l^{-1}, \quad 2=\left[\mathrm{Ca}_{2} T n_{s}\right]$ umolml $\mathrm{m}^{-1}, 3=$ force $(\mathrm{N})$

(c) $1=\left[A_{\alpha}\right]$ umol ml $^{-1}$, representing the non-force generating cross-bridges, $2=\left.\left[A_{\beta}\right] \mu \mathrm{mol} \mathrm{m}\right|^{-1}$, representing the force generating bridges 
Section do not indicate that one of the processes is rate limiting.

\section{Simulation results of intermediate processes}

One of the possibilities with the c.m.a. model is the calculation of the concentrations of calcium in the various compartments during different stimulation patterns.

An action potential, used as model input, is shown in Fig. $8 a$ together with the resulting calcium release flow $\phi_{1}$ starting after the crossing of a transition voltage (constant $\bar{V}$ in eqns. 3 and 4). Its duration is slightly increased with respect to that of the action potential (note this is less than $2 \mathrm{~ms}$ ). The release causes the rise of the sarcoplasmic calcium concentration (Fig. $8 b$ ). The shape of this concentration curve is comparable with the $\phi_{1}$ curve. The resting state sarcoplasmic calcium concentration equals $10^{-5} \mu \mathrm{mol} / \mathrm{ml}$ [referenced to the range from $0.5 \times 10^{-5}$ (SzENTGYÖRGYI, 1975) to $2 \times 10^{-5} \mu \mathrm{mol} / \mathrm{ml}$ (FORD and PODOlsky, 1972) in frog muscle fibres]. The maximum concentration reaches $1.8 \times 10^{-2} \mu \mathrm{mol} / \mathrm{ml}$ after one action potential. The prolonged presence of a concentration six times higher than this is able to introduce full activation (CHANDLER et al., 1976b). The rise in sarcoplasmic calcium concentration is followed by a very fast increase in $\left[\mathrm{Ca}_{2} \mathrm{Tn}_{s}\right]$. This curve reaches its peak value at the end of the $\left[\mathrm{Ca}^{2+}\right]_{s}$ peak and declines slowly thereafter (Fig. 8b). The $\mathrm{Ca}_{2} \mathrm{Tn}_{\mathrm{s}}$ is followed by an increase in the number of cross-bridges, those generating no force $\left(A_{\alpha}\right)$ rising the first (Fig. 8c). Note that the time scales in Figs. $8 b$ and $c$ differ by a factor of 15 , indicating that the reaction rate constants in the cross-bridge processes are essential in the slow pattern of the force. The simulated results were worse in the condition where all the cross-bridges contributed to the force. Two reactions with a reaction rate constant relatively low with respect to the calcium binding to troponin and to calcium transporting ATPase are essential. The time course of $\left[A_{\beta}\right]$ is identical with that of muscle force (see eqn. 15).

The competition between the calcium binding to troponin and the calcium transporting ATPase is indicated by the curves in Fig. 9a. The cross-hatched area is almost equivalent to the amount of calcium that directly is bound to the ATPase. This calcium (about one third of the total amount released) does not contribute to the force generation. The binding of calcium on the ATPase at the sarcoplasmic side of the SR-membrane is fast in contrast to the splitting off at the luminal side of the membrane causing the time course of the calcium flows to and from the ATPase to be very different (Fig. $9 b$ ). In a twitch the flow $\phi_{3}$ will contribute essentially to relaxation which in a tetanus is only driven by $\phi_{4}$ since the occupancy of the ATPase with calcium is maximum at the moment the stimulation stops.

There is still an increased flow within the SR to the cisternae after the mechanical relaxation of the muscle is complete. Comparison of Fig. $9 c$ and $8 c$ illustrates this aspect up to $120 \mathrm{~ms}$. The resting state is reached again only after a time well beyond $1 \mathrm{~s}$ after the start of twitch.

Unfortunately, the experimental data on calcium flows and concentrations are very scarce for

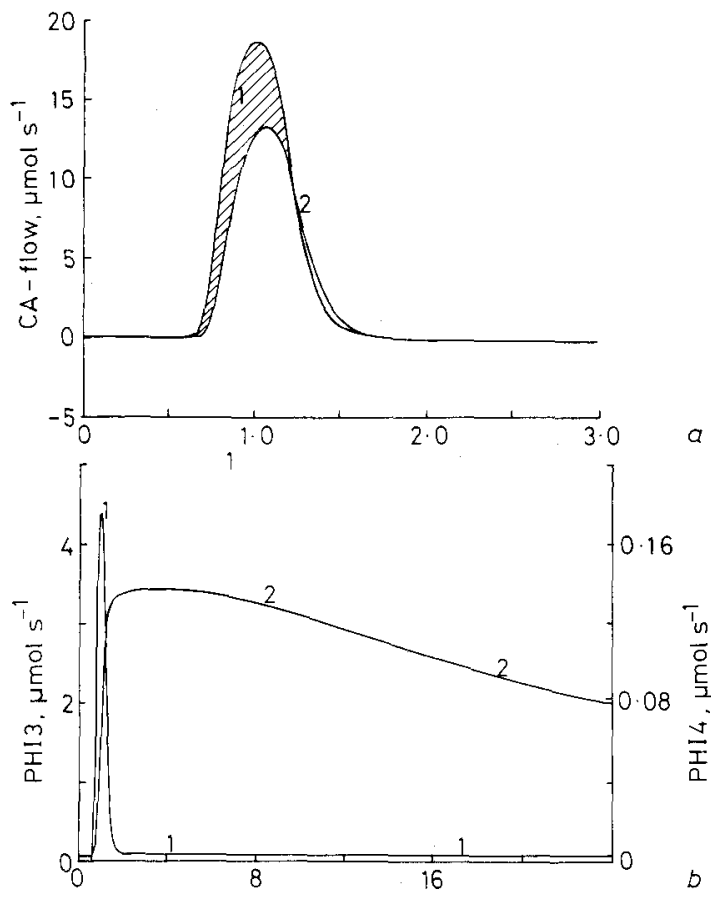

Medical \& Biological Engineering \& Computing

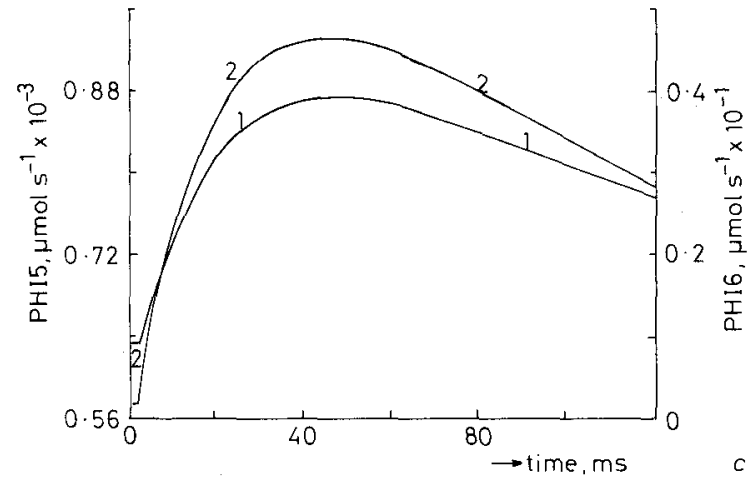

Fig. 9 Calcium flows simulated by the model.

(a) $1=\phi_{1}$, release flow, $2=\phi_{2}$, flow to troponin. The shaded area represents something like the capacity of carriers and sarcoplasm

(b) $1=\phi_{3}$, flow representing the removal of calcium from sarcoplasm by calcium transporting ATPase, $2=\phi_{4}$, flow of calcium from the carrier into the longitudinal SR. Note the different scales

(c) $1=\phi_{5}$, leakage flow from longitudinal $S R$ into sarcoplasm, $2=\phi_{6}$, back flow from longitudinal $S R$ to the terminal cisternae 
mammalian muscle fibres. Data for $\left[\mathrm{Ca}^{2+}\right]_{S}$ are more often described for frog muscle fibres (MILEDI et al., 1977; BLINKS et al., 1978) than for mammalian muscle fibres (EUSEBI et al., 1980). In frog skeletal muscle fibres the light signal with aequorin reaches its crest value about $10 \mathrm{~ms}$ after the onset of the action potential $\left(30^{\circ} \mathrm{C}\right.$; Fig. 3 of BLINKs et al., 1978), but this probably reflects more the kinetics of the aequorin reaction than the calcium transient in sarcoplasm (BLINKS et al., 1978). In our model simulations the action potential is very brief and causes a sharp peak in sarcoplasmic calcium concentration (Fig. 8a), its highest value being reached about $1 \mathrm{~ms}$ after the onset of the action potential $\left(37^{\circ} \mathrm{C}\right)$.

\section{Discussion}

The force generated by skeletal muscle depends mainly on the nature of the muscle fibres of which it is composed, on the stimulation pattern and on the degree of elongation of the muscle. The model presented was developed to study whether the isometric force of a muscle during a number of stimulation patterns could be understood in terms of the processes known to play a role in the excitationcontraction coupling and in force generation. For such an approach it is necessary to realise a model that is based upon physiologically recognisable component processes. Presently available models for skeletal muscle, in which activation processes are implemented, are not sufficiently extensive for this purpose (ASHLEY and MOISESCU, 1972; AKAZAWA et al., 1976; HATZE, 1977; RADU et al., 1974) or are based on obsolete data (TAYLOR, 1969). Such extensive models are also lacking for cardiac muscle, although a related approach such as ours is sometimes taken (BASSINGTHWAIGHTE and REUTER, 1972; KAUFMANN et al., 1974; TSATURYAN and IZAKOV, 1978; MARKHASIN and MiL'SHTEIN, 1979; VAN DEN BROEK, 1979).

Before evaluating the model, the main assumptions and simplifications inherent in the model processes will be discussed in some detail. In contrast to heart muscle fibres, the calcium content of skeletal muscle fibres is independent of the stimulation pattern (KIRBY et al., 1975). Isolated skeletal muscle fibres are able to generate force, even in a calcium free medium (BLINKS et al., 1978). So the calcium flow through the sarcolemma has been neglected.

It is generally accepted that the depolarisation of the tubular membrane is the main cause for calcium release in skeletal muscle fibres (ENDO, 1977). An action potential is propagated along the tubular membranes with a velocity of about $8 \mathrm{cms}^{-1}$ in frog muscle fibres at $20^{\circ} \mathrm{C}$ (GONZALEZ-SERRATOS, 1971). In soleus muscle fibres at $37^{\circ} \mathrm{C}$ this should introduce a delay $<0.25 \mathrm{~ms}$ between superficial and medial tubular membrane depolarisation and consequently between the calcium release in the corresponding myofibrils. It ensures an adequate transversal synchronisation within the fibre, while such a delay will not change the twitch form noticeably (Fig. 7a).

The depolarisation of the tubular membrane determines the number of open calcium channels in the cisternal membranes. This is described by a formalism that might be compatible with the membrane charge movement mechanism (CHANDLER et al., 1976a and b). A relation between the number of open calcium channels in the cisternal membranes and the amount of charge movement has been proposed by several authors (CHANDLER, 1976b; CAPUTO and FERNANDEZ DE Bolaños, 1979; SHLEVIN, 1979), but has not been proved (ADRIAN, 1978). The continuity of membrane layers of T-tubules and cisternae (SOMLYO, 1979) may be an important link in the control of opening calcium channels in the SR membrane by depolarisation of the tubular membrane.

In the model $0 \cdot 14 \mu \mathrm{mol}$ calcium release per millilitre of sarcoplasm is sufficient to reach normal force amplitudes; this amount agrees with estimations from recent experiments (BAYLOR et al., 1979a).

While contraction is triggered by the release of calcium from the cisternae, the relaxation is driven by the calcium uptake by longitudinal SR. The relaxation phase depends strongly on the calcium transport from sarcoplasm to longitudinal SR. Parameter values of the calcium flows involved in this transport are uncertain to a great extent (Table 1). So it is not surprising that there is no agreement on the question as to whether the transport velocity is sufficient for adequate relaxation. WEBER (1971 and FORD and PODOLSKY (1972) expect it will be under in vivo conditions. In our model the transport appears to be sufficient for the realisation of relaxation, but due to the simplicity of the structure of the component that modelled the calcium transport into the SR no general conclusions can be drawn.

After the uptake in the longitudinal SR, the calcium is transported back to terminal cisternae. In a tetanus the repeated release of calcium perceivably diminishes the amount of calcium stored in the cisternae. Were it not replenished the tetanus force would collapse at a certain moment. The diffusion rate constant for the backflow given by WINEGRAD (1970) is not sufficient to overcome such a collapse in our model. With a value of about 100 times that of Winegrad corrected for temperature the plateau phase can hold for at least $200 \mathrm{~ms}$. The calcium backflow has no importance for the twitch and double pulse response, but it will influence both the tetanus and the staircase.

The calcium storage in the cisternae may be considerable since, for the main part, it is present in bound form (MARTONOSI, 1971). The calcium is probably bound to proteins with high calcium binding capacity (MACLENNAN and WONG, 1971). The properties of the interaction between free and bound calcium and the concentration of calcium binding protein as used in our model are described in more detail elsewhere (HEIJINK, 1980). During the resting state the main part of calcium is present in the 
cisternae. The total amount of calcium in the muscle fibres has been estimated to be $0 \cdot 3 \mu \mathrm{mol}$ [equal to $0 \cdot 2$ times the estimated weight of SR membrane protein in mg, MARTONOSI (1971)]. If this amount is reduced, the twitch and double pulse response can be maintained as they were, while the prolonged plateau of the tetanus disappears (HEIJINK, 1980).

The model makes it possible to study the effect of other muscle parameters in the excitation-contraction coupling. For example, examine whether a change from the slow to the fast muscle type parameters is sufficient to realise an adequate fast muscle model (e.g. BRIGGS et al., 1977).

\section{Conclusions}

Present day knowledge enables the realisation of a model containing quantitatively essential processes of excitation-contraction coupling and force generation. Such a model is necessarily specific for one particular type of muscle. The force patterns generated by the model as developed for the m. soleus of the rat after one or two action potentials agree satisfactorily with measured performance of that muscle and in their dependency upon the time intervals used.

The amount of calcium transporting ATPase in the SR membrane is so considerable that its buffer action is appreciable. In the model the ATPase competes strongly with troponin in the binding of the released calcium. The behaviour of the muscle after the second action potential depends strongly on the degree of occupancy of both the troponin and the ATPase with calcium.

A literature search for parameters needed to render the model operational reveals that many data required are incompletely defined or partly conflicting. A model as presented in this study can be used as a guide for further study of the processes involved.

Acknowledgments-The authors wish to thank M. W. La Haye, J. L. M. Muller and T. Schilperoort for their contributions to the model development. The helpful suggestions to the preparation of the manuscript by $\mathbf{J}$. $\mathbf{J}$. Denier van der Gon and A. Crowe are gratefully acknowledged. Our sincere thanks to Truus Steijlen for the assistance. The work was supported in part by a grant from the Netherlands Organisation for the Advancement of Pure Research (ZWO).

\section{References}

Adrian, R. H. and PeACHEY, L. D. (1973) Reconstruction of the action potential of frog sartorius muscle. J. Physiol., 235, 103-131.

ADRIAN, R. H. (1978) Charge movement in the membrane of striated muscle. Anh. Rev. Biophys. Bioeng., 7, 85-112.

Akazawa, K., Yamamoto, M., Fujh, K. and Mashima, H. (1976) A mechanochemical model for the steady and transient contractions of the skeletal muscle. Jap. $J$. Physiol., 26, 9-28.

Ashley, C. C. and Molsescu, D. G. (1972) Model for the action of calcium in muscle. Nature New Biol., 237, 208211.
Bassingthwaighte, J. B. and Reuter, H. (1972) Calcium movements and excitation-contraction coupling in cardiac cells. In Electrical phenomena in the heart, DE MELLO, W. C, (Ed.) Academic Press, New York.

Baylor, S. M., Chandler, W. K. and Marshall, M. W. (1979a) Arsenazo III signals in singly dissected frog twitch fibres. $J$. Physiol., 287, 23-24P.

Baylor, S. M., Chandler, W. K. and Marshall, M. W. $(1979 b)$ Arsenazo III signals in frog muscle. Biophys. J., 25 , 141 a.

Bendall, J. R. (1969) Muscles, molecules and movement, Heineman, London.

Blinks, J. R., RÜDEL, R. and TAYLOR, S. R. (1978) Calcium transients in isolated amphibian skeletal muscle fibres: detection with aequorin. J. Physiol., 277, 291-323.

Briggs, F. N., Poland, J. L. and Solaro, R, J. (1977) Relative capabilities of sarcoplasmic reticulum in fast and slow mammalian skeletal muscles. J. Physiol., 266, 587594.

Broek, J. H. J. M. vaN DEN (1979) A model study of left ventricular function. Thesis State University of Utrecht, The Netherlands.

Caputo, P. and Fernandez de Bolaños, P. (1979) Membrane potential, contractile activation and relaxation rates in voltage clamped short muscle fibres of the frog. $J$. Physiol., 289, 175-189.

Chandler, W. K., Rakowski, R. F. and Schneider, M. F. (1976a) A non-linear voltage dependent charge movement in frog skeletal muscle. $J$. Physiol., 254, 245-283.

Chandler, W. K., Rakowski, R. F. and Schneider, M. F. (1976b) Effects of glycerol treatment and maintained depolarization on charge movement in skeletal muscle. $J$. Physiol, 254, 285-316.

EISENBERG, B. R. and KUDA, A. M. (1976) Discrimination between fiber populations in mammalian skeletal muscle by using ultrastructural parameters. J. Ultrastruct. Res., 54, 76-88.

ENDo, M. (1977) Calcium release from the sarcoplasmic reticulum. Physiol. Rev., 57, 71-108.

Eusebi, F., Miledi, R. and TAKahashi, T. (1980) Calcium transients in mammalian muscles. Nature, 284, 560-561.

Ford, L. E. and Podolsky, R. J. (1972) Calcium uptake and force development by skinned muscle fibres in EGTA buffered solutions. J. Physiol., 223, 1-19.

Franzini-Armstrong, C. (1970) Studies of the triad: I. Structure of the junction in frog twitch fibres. J. Cell Biol., 47, 488-499.

Froehlich, J. P. and TAYlor, E. W. (1975) Transient state kinetic studies of sarcoplasmic reticulum adenosine triphosphatase. J. Biol. Chem., 250, 2013-2021.

Fuchs, F. (1974) Striated muscle. Ann. Rev. Physiol, 36, 461502.

GONZALEZ-SERRATOS, H. (1971) Inward spread of activation in vertebrate muscle fibres. $J$. Physiol, 212, 777-799.

GrAY, B. F. and GONDA, I. (1978) The sliding filament model of muscle contraction II. The energetic and dynamical predictions of a quantum mechanical transducer model. $J$. Theor. Biol., 69, 187-230.

Haiech, J., Derancourt, J., Pechère, J-F. and Demaille, J. G. (1979) Magnesium and calcium binding to parvalbumins: evidence for differences between parvalbumins and an explanation of their relaxing function. Biochemistry, 18, 2752-2758.

HANSON, J. (1974) The effects of repetitive stimulation on the action potential and the twitch of rat muscle. Acta Physiol. Scand., 90, 387-400.

HATZE, H. (1977) A myocybernetic control model of skeletal 
muscle. Biol. Cybernetics, 25, 103-119.

HeiJink, R. J. (1980) A contribution to the development and parameter estimation of a calcium mediated activation model for rat skeletal muscle. Research report nr. 219, Bioinformation Group, Twente University of Technology, The Netherlands.

HuXley, A. F. (1974) Muscular contraction. J. Physiol, 243, $1-43$.

Johnson, J. D., Charlton, S. C. and Potter, J. D. (1979) A fluorescence stopped flow analysis of $\mathrm{Ca}^{2+}$ exchange with troponin C. J. Biol. Chem., 254, 3497-3502.

Julian, F. J., Sollins, K. R. and Sollins, M. R. (1974) A model for the transient and steady-state mechanical behavior of contracting muscle. Biophys. J., 14, 546-562.

Kanazawa, T., Yamada, S., Yamamoto, T. and Tonomura, Y. (1971) Reaction mechanism of the $\mathrm{Ca}^{2+}$-dependent ATPase of sarcoplasmic reticulum from skeletal muscle. V. Vectorial requirements for calcium and magnesium ions of three partial reactions of ATPase: formation and decomposition of a phosphorylated intermediate and ATP-formation from ADP and the intermediate. $J$. Biochem., 70, 95-123.

Kaufmann, R., Bayer, R., Furniss, T., Krause, H. and TritTharT, H. (1974) Calcium-movement controlling cardiac contractility II. Analog computation of cardiac excitation-contraction coupling on the basis of calcium kinetics in a multi-compartment model. J. Mol. Cell. Cardiol., 6, 543-559.

Kirby, A. C., Lindley, B. D. and PiCken, J. R. (1975) Calcium content and exchange in frog skeletal muscle. $J$. Physiol., 253, 37-52.

LuFf, A. R. and ATwood, H. L. (1971) Developmental changes in the sarcoplasmic reticulum and transverse tubular system in skeletal muscle of the mouse. J. Gen. Physiol., 57, 243-244.

MACLENNAN, D. H. and WONG, P. T. S. (1971) Isolation of a calcium-sequestering protein from sarcoplasmic reticulum. Proc. Nat. Acad. Sci., USA, 68, 1231-1235.

Markhasin, V. S. and Mill'shtein, G. N. (1979) Modelling the influence of rhythm on the force of contraction of heart muscle. Biophysics, 23, 688-696.

Martonosi, A. (1971) The structure and function of sarcoplasmic reticulum membranes. In Biomembranes, Manson, L. (Ed.), Vol. I, 191-256, Plenum, New York.

MARTonosi, A. (1973) Biochemical and clinical aspects of sarcoplasmic reticulum function. In Topics in membranes and transport, BronNER, F. and KLEINZELLER, A. (Eds.), 3, 83-197, Academic Press, New York.

Martonosi, A., Lagwinska, E. and Oliver, M. (1974) Elementary procedure in the hydrolysis of ATP by sarcoplasmic reticulum membranes. Ann. N.Y. Ac. Sci., 227, 549-567.

Mrledi, R., Parker, I. and Schalow, G. (1977) Measurements of calcium transients in frog muscle by the use of arsenazo III. Proc. R. Soc. Lond. B., 198, 201-210.

OGAWA, Y. (1970) Some properties of fragmented frog sarcoplasmic reticulum with particular reference to its response to caffeine. J. Biochem., 67, 667-683.

PERRY, S. V. (1979) The regulation of contractile activity in muscle. Biochem. Soc. Trans., 7, 593-617.

PotTer, J. D. (1979) Personal communication.

Potter, J. D. and Gergely, J. (1975) The calcium and magnesium binding sites on troponin and their role in the regulation of myofibrillar adenosine triphosphatase. $J$. Biol. Chem., 250, 4628-4633.

Potter, J. D., Johnson, J. D. and Robertson, S. P. (1978) Studies on the regulation of skeletal and cardiac muscle contraction. 6th International Biophysics Congress, Kyoto, p. 235.

Radu, H., Da Ronch, A. and Caldesi-Valeri, V. (1977) Calcium and myotonia: a mathematical model. Bull. Math. Biol., 39, 577-585.

SHLEvin, H. H. (1979) Effects of external calcium concentration and $\mathrm{pH}$ on charge movement in frog skeletal muscle. J. Physiol, 288, 129-158.

SOMLyO, A. V. (1979) Bridging structures spanning the junctional gap at the triad of skeletal muscle. J. Cell Biol., 80, 743-750.

Stonnington, H. H. and EngEl, A. G. (1973) Normal and denervated muscle. A morphometric study of fine structure. Neurology, 23, 714-724.

Sumida, M., Wang, T., Mandel, F., Froehlich, J. P. and SCHWARTZ, A. (1978) Transient kinetics of $\mathrm{Ca}^{2+}$ transport of sarcoplasmic reticulum. A comparison of cardiac and skeletal muscle. J. Biol. Chem., 25, 8772-8777.

SzENT-GYÖRGYI, A. G. (1975) Calcium regulation of muscle contraction. Biophys. J., 15, 707-723.

TAda, M., Yamamoto, T. and Tonomura, Y. (1978) Molecular mechanism of active calcium transport by sarcoplasmic reticulum. Physiol. Rev., 58, 1-79.

TAYLOR, C. P. S. (1969) Isometric muscle contraction and the active state: an analog computer study. Biophys. $J ., 9,759$ 780 .

Tsaturyan, A. K. and Izakov, V. Ya. (1978) Mathematical model of the coupling of excitation with contraction in the heart muscle. Biophysics, 23, 904-910.

WALKER, S. M. and SCHRODT, G. R. (1969) Filament lengths and distribution of staining material in the I-bands of rat skeletal muscle. Am. J. Phys. Med., 48, 178-192.

Wallinga-DE JONGE, W. (1980) Force development in rat skeletal muscle-measurement and modeling. Thesis, Twente University of Technology, The Netherlands.

Wallinga-de Jonge, W., BoOm, H. B. K., Bóon, K. L., Griep, P. A. M. and Lammerée, G. C. (1980) The force development of fast and slow skeletal muscle at different muscle lengths. Am. J. Physiol., 239 (Cell Physiol. 8), C98C104.

WEBER, A. (1971) Regulatory mechanisms of the calcium transport system of fragmented rabbit sarcoplasmic reticulum. I. The effect of accumulated calcium on transport and adenosine triphosphate hydrolysis. J. Gen. Physiol, 57, 50-63.

Weber, A., Herz, R. and Reiss, I. (1966) Study of the kinetics of calcium transport by isolated fragmented sarcoplasmic reticulum. Biochem. Z., 345, 329-369.

Winegrad, S. (1970) The intracellular site of calcium activation of contraction in frog skeletal muscle. J. Gen. Physiol., 55, 77-88. 